\title{
Local Communities' Attitude Toward Community Based Forest Management: The Case of Jello Forest, West Hararghe Zone, Oromia Regional State, Ethiopia
}

\author{
Mufedei Mohammed Kasim*, Najib Umar Hussen \\ College of Natural Resource and Environmental Science, Oda Bultum University, Chiro, Ethiopia \\ Email address: \\ mufaddalmohammed@yahoo.com (M. M. Kasim) \\ ${ }^{*}$ Corresponding author \\ To cite this article: \\ Mufedei Mohammed Kasim, Najib Umar Hussen. Local Communities' Attitude Toward Community Based Forest Management: The Case \\ of Jello Forest, West Hararghe Zone, Oromia Regional State, Ethiopia. American Journal of Environmental Protection. Special Issue: \\ Enhancing Natural Resource Conservation for Sustainable Development. Vol. 8, No. 4, 2019, pp. 78-86. doi: 10.11648/j.ajep.20190804.11
}

Received: August 12, 2019; Accepted: August 26, 2019; Published: September 11, 2019

\begin{abstract}
Managing forest through local participation is a phenomenon that emerged over recent decades as a remedial measure to the old (top down) form of forest management. One of the core concepts in this Participatory forest management (PFM) is improving sense of ownership by empowering forest dependent communities as both developer and beneficiaries of forest resources. Accordingly this research was under taken on Jello forest in Western Hararghe zone, Oromia regional state, with the objective of studying local communities' attitude towards PFM approach and improvements in the forest dependent communities sense of ownership toward the forest. A total of 172 sampled respondents were randomly selected from both nonPFM and PFM member households. Data were collected from sampled households using Household survey questionnaire, key informant interview and focus group discussion. Qualitative data were analyzed using content and discourse analyses; whereas quantitative data were analyzed by descriptive statistics using R-statistical software. Accordingly the result of household survey, focus group discussion and key informant interview were revealed that local communities have positive attitude towards PFM and after the PFM was introduced local communities' sense of ownership toward the forest has significantly improved. About $70 \%$ of non- PFM and $85 \%$ of PFM members were strongly agreed that the establishment of PFM has improved local communities' sense of ownership towards the forest. Based on the findings of this study it could be concluded that PFM is effective in improving local communities sense of ownership towards the forest an effectively compensate the short comings of centralized forest management system.
\end{abstract}

Keywords: Participatory Forest Management, Attitude, Participation, Sustainable Development, Jello Forest

\section{Introduction}

Forest provides extraordinarily vast and far-reaching contribution to the well-being of humankind. It play a fundamental role in combating rural poverty, ensuring food security and providing decent livelihoods; they offer promising mid-term green growth opportunities; and they deliver vital long-term environmental services, such as clean air and water, conservation of biodiversity and mitigation of climate change [1]. However, the unwise intervention resulted in the continuous loss of forest cover area in many parts of the world causing problems to human life [1].

The estimation made by Forest and Agricultural
Organization of UN report [2], states that, the age of deforestation goes back as early as human civilization. Current assessment indicates that, for over the past 25 years (i.e. 1990-2015) alone, our world has experienced the net loss of some 129 million ha of forests (natural and planted) representing a total area about the size of South Africa [1]. The biggest proportion of forest area loss during this time has occurred in the tropics, particularly in South America and Africa [1].

Being one of the developing countries in Africa, Ethiopia is exceptionally rich in cultural and biological diversity. However, this rich cultural and natural heritage is threatened [3]. Even though, Ethiopia's deforestation rate is about 
average when compared to other east African countries, deforestation rates and decline in forest conservation in region are the second largest in the African continent [3]. Historical source indicates that about 42 million ha or equivalent of $35 \%$ of Ethiopia's total land area had been covered with forests [4]. The estimate further indicates that, in the early 1950, the remaining forest covered 19 million ha or $15 \%$ of the land area. In the early 1980 , coverage was reported at $3.6 \%$ and in the 1989 it was estimated to be only $2.7 \%[5]$.

In accounts of the increasing human and livestock population, the demand for forest products and forest land for the expansion of farm and grazing lands has increased in Ethiopia over the last decades [6]. This coupled with the ineffective forest management efforts over the past [7] has resulted in over exploitation of forest resources in Ethiopia.

It is obvious that the importance of forest resources to human life and the degradation resulting of human intervention brings the issue of forest management into the fore front. Accordingly the continued deforestation and forest degradation in Ethiopia, despite the long time government's effort to deal with the problem, stimulated the concern to look for alternative means of forest management. The old approach (top-down) that sought to halt forest exploitation through expropriation of forest dependent communities and by enacting laws to reduce human impacts on forests, proved itself disincentive in terms of managing resource productively and sustainably. Amogne Asfaw [8] stated that, the most negative environmental impact in Ethiopia, during the Derge regime (1974-1991), came from policy and regulatory interventions that cumulatively eroded the rights of individuals and communities to use and manage their own resources. The old approach that was mainly focused on prohibitive rules, that denies access rights of the local people, came to erode the age old customary practices which have maintained forest resources [9]. As the result, local peoples were conditioned to develop a feeling of hostility that eroded sense of ownership toward the forests. This situation let the forests remain without an owner, given the absence of formal and informal institution that could guard forests from various illegal activities.

As an alternative means to deal with the shortcoming of the Top-down approach, in which government plays the central role, the Bottom-up approach emerged, in which local communities play central role $[10,11]$. PFM is one of these participatory and sustainable use approaches which have demonstrated magnificent results in protecting forest resources and contributing to the livelihood means of the local people [9]. The central premise of PFM approach is that, local communities who live in close proximity to a forest possess an inherent capacity, knowledge and interest to govern their resources properly $[12,11]$. Accordingly in PFM under the terms of agreement between government and local communities, forest management responsibilities and use rights will be granted to local communities with technical support being provided from government and nongovernment (NGOs) stakeholders [11]. Similarly PFM was introduced in to Ethiopia through NGOs and government agencies to deal with the persistent problems of deforestation and to deliver better social and economic outcomes compared with the former centralized command-and-control resource management approach [13, 14].

In 2007, Oromia regional state has established forest enterprises with a supervising agency, and restructured it in to Oromia Forest and Wildlife Enterprise (OFWE) since 2009. OFWE manages all state forests and many natural forests through PFM arrangement in Oromia. Accordingly through its sub-branch office of Hararge zone and in cooperation with nongovernmental organization (i.e. AMBERO-GITEC/GTZ) OFWE initiated PFM project in Jello forest with the intention to halt deforestation through devolution of power between government (forestry department) and local communities and thereby empowering local communities; boosting their sense of ownership to manage and use forests responsibly. Given the establishment of PFM at Jello forest as sustainable means to deal between poverty alleviation and forest conservation; by enhancing local communities' participation and improving their sense of ownership towards the forest; a study can help to strengthen the approach by elaborating over issues pertaining to the success and failure of the project. To this end, this research tries to assess the effectiveness of participatory forest management (PFM) in improving local communities' attitudes toward the forest management. To our knowledge no research has been carried out so far under the current title and this research tries to fill this gap and there by tries to contribute to the existing body of knowledge.

\section{Method}

\subsection{Description of the Study Area}

\subsubsection{Location}

The study was conduct on Jello Forest which is situated in Jello-Muktar State Forest Priority Area at about $332 \mathrm{kms}$ southeast of Addis Ababa. Geographically located at $8^{\circ} 55^{\prime} \mathrm{N}$ latitude and $40^{\circ} 50^{\prime} \mathrm{E}-40^{\circ} 51^{\prime} \mathrm{E}$ longitude. The forest shares boundaries in North and East with Chiro district, in the South-east with Gemechis district and in the west with Oda Bultum district [15].

\subsubsection{Climate}

Jello forest area is found at an altitude ranging between 2000 and 3074masl. It has a subtropical climate condition with mean annual temperature of $15^{\circ} \mathrm{C}$ and mean rainfall of $1220 \mathrm{~mm}$. The length of growing period ranges from 210-270 days [16]. The rain fall pattern is bimodal, with the short rainy season from February to March and the main rainy season from March to July [17].

\subsubsection{Soil}

The soil of the study aria is mainly made up of basaltic rock formation that resulted from the formation of two main soil types. On the flat plateau and wide valley bottom, there are heavy clay soils-which is black cotton soil and on the 
slopes reddish brown loam which are comb soils [15].

\subsubsection{Vegetation}

The forest in the study is mainly characterised by dry afromountain forest; and covering an area of around 7820 ha. Some of the characteristic tree and shrub species include: Podocarpusfalcatus, Juniperus excels, Vernonia spp., Rosa abyssinica, Bersema abyssinica, Dodonaeaaugostifolia, Haginia abyssinica and others [15, 18].

\subsubsection{Socio-Economic Conditions}

According to the 2007 Population and Housing Census of Ethiopia, the human population of the area was estimated to be 184,238 of which 180,375 were living in the rural and 3863 , in urban.. The majorities of the communities belong to Oromo tribe and are followers of Muslim religion. The farming systems are mainly characterized by the presence of subsistence mixed farming, of both livestock and agricultural crop production. There are also many households engaged in Participatory Forest Management (PFM) and attaining their livelihood through various NTFP related activities like bee keeping, controlled hunting and pasture sell. Some of the households do not have land. The forest is the main source of fuel wood demand for the whole communities. It is also the main source of livelihood for some of households. Volunteer migration of adults is the other common livelihood strategy in Quni-Sororo area. Initially it was invented by farmers themselves after obtaining unoccupied cultivable land in Bale region, south eastern Ethiopia. The major crop grown in the aria is sorghum-hoe and maize and minor crops are teff. About $95 \%$ of the total population grows crops and rear livestock to supplement with crops and for draught animals (oxen used for traction) for agriculture [19]. Generally, the main sources of income for the local communities are selling of crops, livestock and forest products.

\subsubsection{Brief History of Jello Forest}

The Jello Forest Area was once covered by tropical highland forests in south eastern Ethiopia. During the imperial regime, foreign private organization planted forest miller in the sub-catchment for timbering [19]. After timber plant failed to continue due to deforestation, smallholding farmers encroached to the mountain forest area for settlement, farming and livestock production. After severe deforestation, around early 1980s, it becomes state forest protection area where plantation of monoculture afforestation occurred [19]. Common-resource management approach was implemented where farmers freely encroached for farming, livestock rearing, domestic and commercial purposes. This aggravated by frequent changes of government and gap in administrative roles of central government, namely early 1970s and 1990s [19]. It was one of the areas in the Hararghe Highlands of Ethiopia where Community Forestry Practices (CFP) projects are undertaken.

Since 2009, PFM approach initiated by the Oromiya Forestry and Wildlife Agency in collaboration with the German Technical Corporation (namely GTZ) with active participation of all stakeholders and the local community.
There is eco-tourism due to wild animals like Mountain Nyala, Menelik Bush Buch, Leopard, Hyena, Rhinoceros, Black and White Monkeys, and numerous birds. Inventory of wild animals is conducted by experts from Federal Government and community representatives. Based on their quota, controlled-hunting of Mountain Nyala and Leopard is permitted for tourists. Community closer to the forest land organized into Community Forest Association (CFAs) based on proximity, small landholding, poor economic status, volunteer to participate in the program. Activities of the CFAs include bee keeping, livestock fattening, following up zero-grazing, cut and carry system of grass and collection of income from eco-tourism. CISP-Ethiopia (International Committee for the Development of PeoplesItalian Based NGO) is acknowledged for support of the CFAs with initial capital on gift and on credit basis to be refunded after grace period of two and half years. It also provided necessary funds for materials and construction of livestock fattening shelters in the area. At the current time, locals are benefiting from the forest and rehabilitation of forest cover became apparent.

\subsection{Sampling Method}

Sample size was determined by using sample size determination formula $\mathrm{n}=\mathrm{N} /\left(1+\mathrm{N}^{*} \mathrm{e}^{2}\right)$ adopted from [20]. In this case, $\mathrm{n}$ stands for sample size, $\mathrm{N}$ for total households (HHs) and e represent level of precision. With 95\% confidence level and an error limit of 5\%. Accordingly, 86 PFM members and an equivalent number from non-PFM householdtotalling172 have been selected.

The sampled households were randomly selected by using PFM group members list from the three PFM blocks (Chefe, Wesene and Gende-dara) found in Sororo kebele and an equivalent number of households from non-PFM were randomly selected from the same kebele.

\subsection{Methods of Data Collection}

\subsubsection{Data Source}

For this research purpose, both primary and secondary data were used. Primary data was collected through key informant interview, focus group discussion and household survey. The source of secondary data include published and unpublished material references such as: books, journals, project reports and maps.

\subsubsection{Data Collection Tools}

Key Informants: Key informants who have deep knowledge of their locality were selected through snowball methods and the information collected was used as an input for group discussion and for developing questionnaire for households' survey. Those key informants were forestry expert at district level, chair person of FUG cooperatives, community leader and female representative.

Focus Group Discussion: The participant for focus group discussions were selected on the basis of their knowledge of PFM activities and position in the PFM cooperative. Accordingly, four focus group discussions 
with number of participants ranging from 8 persons to 12 persons were undertaken. Within the three focus group discussion held in each three PFM blocks, Participants were both female and male members of PFM; and one focus group discussion is only composed of female members of PFM. Female group discussion was undertaken to discover effect of PFM on women's participation. PFM participant members list were used to select respondents. The collected data was mainly used to assess community's attitude towards PFM approach.

Household Survey: A total 172 households both from PFM blocks and non-PFM members were used for the survey. Socio-economic data were collected through questionnaire composed of both closed and open ended question divided into three sections and six subsections in general. Each subsection has 5 to 16 closed ended questions, based on Likert-Scale model, in addition with one or two open ended questions to get the context. The questionnaire was pre-tested to check wither it is easy to be understood by the respondents and capable of collecting the required data. Furthermore, the questionnaire was translated into local language Afan Oromo and it was presented to the respondents verbally (with the consideration that majority of the farmers cannot read and write). In order to facilitate this, three enumerators were drawn from the locality with minimal educational level of $10^{\text {th }}$ grade and were trained. The collected data was used to study attitude towards PFM and its ecological effects.

\subsection{Data Analysis}

Data collected through key informant interview and focus group discussion were analysed using content analyses. The responses of the key informants and records of Focus Group Discussions were coded and analyzed using content and discourse analysis methods. Accordingly, relevant themes and concepts were identified and summarized. The household survey data were also analysed using descriptive statistics like mean, frequency, percentages, standard deviation, etc; and presented using tables and bar graphs. Supporting tool for the analyses was R statistical software.

\section{Results and Discussion}

\subsection{Socio-Economic Characteristics of Respondents}

The results of this study indicate that, household size of PFM members and non-PFM ranges from 2-11 and 3-10 members respectively. Mean household size recorded for PFM and non-PFM households were similar average household being 6.36 and 6.29 members respectively. The mean household sizes of participants in adults age class were slightly larger compared to those of the young age class. For households in the young age class mean size was 5.14 and 4.8 members for PFM and non-PFM respectively, while for households in adult age class households mean size of PFM the mean household size were 6.7 and 7.0 members for PFM households and no-PFM households respectively (Table 1).

Table 1. Household size of different age classes and corresponding farm land holdings.

\begin{tabular}{|c|c|c|c|c|c|c|}
\hline \multirow{2}{*}{$\begin{array}{l}\text { Age-class by } \\
\text { years }\end{array}$} & \multicolumn{3}{|c|}{ PFM households $(n=86)$} & \multicolumn{3}{|c|}{ Non-PFM households $(n=86)$} \\
\hline & description & family size & Landholding (ha) & description & family size & Landholding (ha) \\
\hline \multirow{3}{*}{ Young18-30 } & Mean & 5.14 & 0.33 & Mean & 4.8 & 1 \\
\hline & minimum & 2 & 0.25 & minimum & 3 & 1 \\
\hline & maximum & 8 & 0.5 & maximum & 8 & 1 \\
\hline \multirow{3}{*}{ Adult31-55 } & Mean & 6.7 & 0.37 & Mean & 7 & 2.05 \\
\hline & minimum & 4 & 0.25 & minimum & 4 & 1 \\
\hline & maximum & 11 & 1.00 & maximum & 10 & 3 \\
\hline \multirow[t]{2}{*}{ Old $>55$ years } & minimum & - & - & minimum & - & - \\
\hline & maximum & - & - & maximum & - & - \\
\hline \multirow{3}{*}{ Total } & Mean & 6.36 & 0.31 & Mean & 6.29 & 1.68 \\
\hline & minimum & 2 & 0.25 & minimum & 3 & 1 \\
\hline & maximum & 11 & 1.00 & maximum & 10 & 3 \\
\hline
\end{tabular}

The result of this study also indicates that the overall landholding of sampled households range from 0.25 ha of land to $3 \mathrm{ha}$; and the overall mean of farm land owned by the respondents was 0.95 ha. However, there was a difference between the mean number of farm land owned by PFM and non-PFM households. PFM households had 0.31 ha farm land on average while non-PFM households had 1.68 ha farm land on average. Accordingly non-PFM members owned more hectares of farm lands compared to PFM members. Similarly an interview with forest experts revealed that, land holding was one of the major criteria for household enrolment into PFM. Difference in landholding was also detected between young respondents of PFM households and non-PFM households. The mean landholding for young age class respondents of PFM and non-PFM households were 0.33 and 1 ha respectively. Furthermore, the result indicates that the average landholding for adult age class respondents of PFM and non-PFM members was different. Accordingly the mean landholding for adult age class of both PFM and non-PFM were 0.37 and 2.05 ha respectively (Table 1).

The percentage of landholding (ha) varies between age classes of PFM household and non-PFM households. About $64 \%$ and $36 \%$ of PFM respondents within young age class were owned 0.25 and 0.5 ha of farm lands respectively. Unlike PFM households, all (100\%) of non-PFM households' belonging to young age class were owned 1 ha of farm land. However, difference was detected among PFM households belonging to adult age class. Accordingly, about $70.6 \%$ of 
adult age households were owned 0.25 ha followed by $19 \%$ and $10 \%$ of households owning 0.5 and 1 ha of farmlands respectively. In adult age class of non-PFM households' landholding (ha) varies from 1 ha to 3 ha of farm lands.
Accordingly $62.5 \%$ of households were owned 2 ha of farm lands followed by $23.2 \%$ and $14.2 \%$ of households owning 1 ha and 3 ha of farm land respectively (Table 2 ).

Table 2. Percentage of landholding (ha) by age classes.

\begin{tabular}{|c|c|c|c|c|c|c|c|c|c|c|}
\hline \multirow{2}{*}{ Age class of Households' } & \multicolumn{5}{|c|}{ PFM Households' Land holding (ha) } & \multicolumn{5}{|c|}{ Non-PFM Households' Land holding (ha) } \\
\hline & 0.25 ha & 0.5 ha & 1 ha & 2 ha & 3 ha & 0.25ha & 0.5 ha & 1 ha & 2 ha & 3 ha \\
\hline Young & $64 \%$ & $36 \%$ & $0 \%$ & $0 \%$ & $0 \%$ & $0 \%$ & $0 \%$ & $100 \%$ & $0 \%$ & $0 \%$ \\
\hline Adult & $70.6 \%$ & $19 \%$ & $10 \%$ & $0 \%$ & $0 \%$ & $0 \%$ & $0 \%$ & $23.2 \%$ & $62.5 \%$ & $14.2 \%$ \\
\hline Old & - & - & - & - & - & - & - & - & - & - \\
\hline
\end{tabular}

In addition, the result indicates that $68.6 \%$ of PFM households owned 0.25 ha of farm land followed by $24.4 \%$ and $7 \%$ of households owning 0.5 and 1 ha of farm lands respectively. According to non-PFM respondents, about 50.0\% households' owned 1 ha followed by $40.0 \%$ and $9.30 \%$ of households owning 2 and 3 ha of farm land respectively.
Furthermore, the result indicates that $34.3 \%$ of the total sampled households were owned 0.25 ha of farm land. Those households who owned 0.5 and 1 ha of farmland were $12.2 \%$ and $28.4 \%$ of the total sampled households respectively. The result further indicated that about $4.65 \%$ of the total sampled households owned 3 ha of farm lands (Table 3 ).

Table 3. Percentage of landholding (ha) for total sampled households.

\begin{tabular}{|c|c|c|c|c|c|}
\hline \multirow{2}{*}{ Membership of Households } & \multicolumn{5}{|c|}{ Landholding (ha) } \\
\hline & 0.25 ha & 0.5 ha & 1 ha & 2 ha & 3 ha \\
\hline $\operatorname{PFM}(n=86)$ & $68.6 \%$ & $24.4 \%$ & $7 \%$ & $0.00 \%$ & $0.00 \%$ \\
\hline Non-PFM (n=86) & $0.00 \%$ & $0.00 \%$ & $50.0 \%$ & $40.6 \%$ & $9.30 \%$ \\
\hline Total $(n=172)$ & $34.3 \%$ & $12.2 \%$ & $28.4 \%$ & $20.3 \%$ & $4.65 \%$ \\
\hline
\end{tabular}

\subsection{Attitudes Towards PFM and Ecological Effects of PFM}

\subsubsection{Attitude Towards PFM}

Attitude is defined as the evaluative dimension of a concept [21]. It is a summarized evaluation of a concept (attitude object) along dimensions such as good-bad, harmful-beneficial, pleasant-unpleasant and likeabledislikeable [22]. The ability of attitudes to predict behavioural intention made them a major focus of theory and research [22]. Attitudes can be used to predict people's behaviour, their responses, acceptance or reaction to development and conservation and thus can serve as points of entry to change the behaviour and commitment of local communities towards natural resource conservation [23]. Furthermore, as stated by Campbell et al [24], participation of local people in decision making and management activities is in itself an important way of forming a favourable attitude towards conservation. In this regard participatory forest management (PFM) is atypical example of forest conservation strategy that promotes local community's participation in the forest management as a way of forming positive attitude towards the conservation of the forest. To this end this research tries to examine local people's attitude towards participatory forest management. Accordingly the results of likert scale Data collected through household survey from both PFM and non-PFM households indicates that, majority of the people have positive attitudes towards the PFM. Responses of the respondents were analyzed using likeret scale analyses based on colored figure (Figures 1 and 2). The figure indicates percentage of the responses for each attitude testing questions based on different colors standing for different responses of the respondents.

As the result indicates about $85 \%$ and $10 \%$ of the respondent from the PFM household's were answered strongly agree and agree respectively that PFM has improved sense of ownership towards the forest; while about $70 \%$ and $30 \%$ of the non PFM households were answered strongly agree and agree that PFM has improved sense of ownership. Only $5 \%$ of the respondents from PFM members were disagreed that the establishments of PFM has improved peoples sense of ownership towards the forest. From both PFM and non-PFM members about $67 \%$ and $73 \%$ respectively were agreed that PFM has improved the livelihood of PFM participant households while $33 \%$ and $14 \%$ of PFM and non-PFM households respectively were disagreed.

In addition, about $64 \%$ and $67 \%$ of PFM and non-PFM households respectively stated that they strongly agree PFM is good to deal with deforestation and poverty. Whereas about $35 \%$ and $33 \%$ of PFM and non-PFM respondents respectively agreed that PFM is good to deal with deforestation and poverty. About $67 \%$ and $76 \%$ of PFM and non-PFM respondents, respectively, stated that they strongly agree PFM compensates the shortcoming of prior forest management while $33 \%$ and $24 \%$ of PFM and non-PFM respondents respectively answered that they agree PFM compensate prior forest management. Furthermore, $67 \%$ of both PFM and non-PFM respondents were also strongly agreed that PFM achieves sustainable use of forest resources; and also $33 \%$ of respondents from both groups agreed the same (Figures 1 and 2). 
83 Mufedei Mohammed Kasim and Najib Umar Hussen: Local Communities' Attitude Toward Community Based Forest Management: The Case of Jello Forest, West Hararghe Zone, Oromia Regional State, Ethiopia

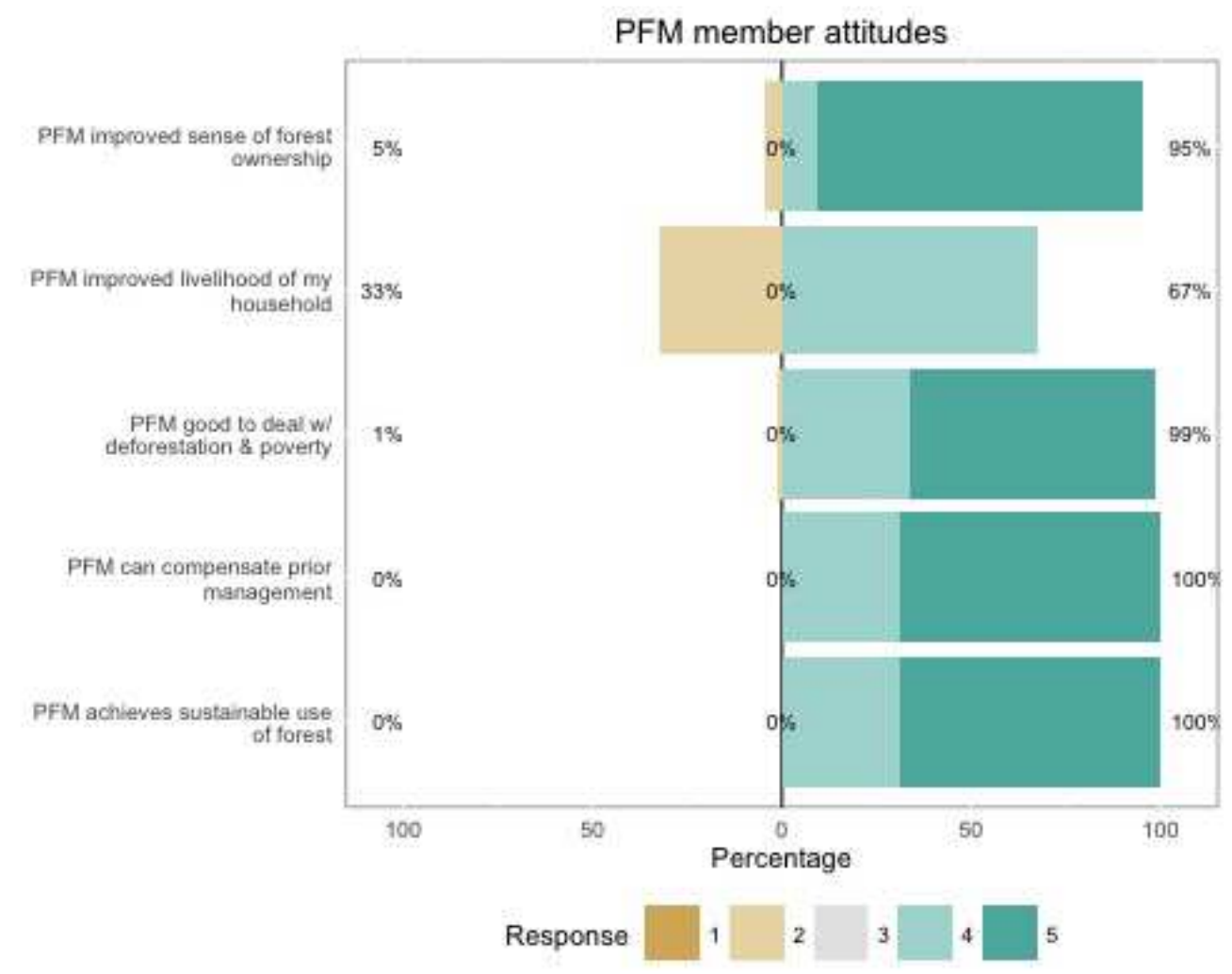

Note: $1=$ Strongly Disagree $2=$ Disagree $3=$ neutral $4=$ Agree $5=$ Strongly Agree

Figure 1. PFM household's attitude towards PFM.

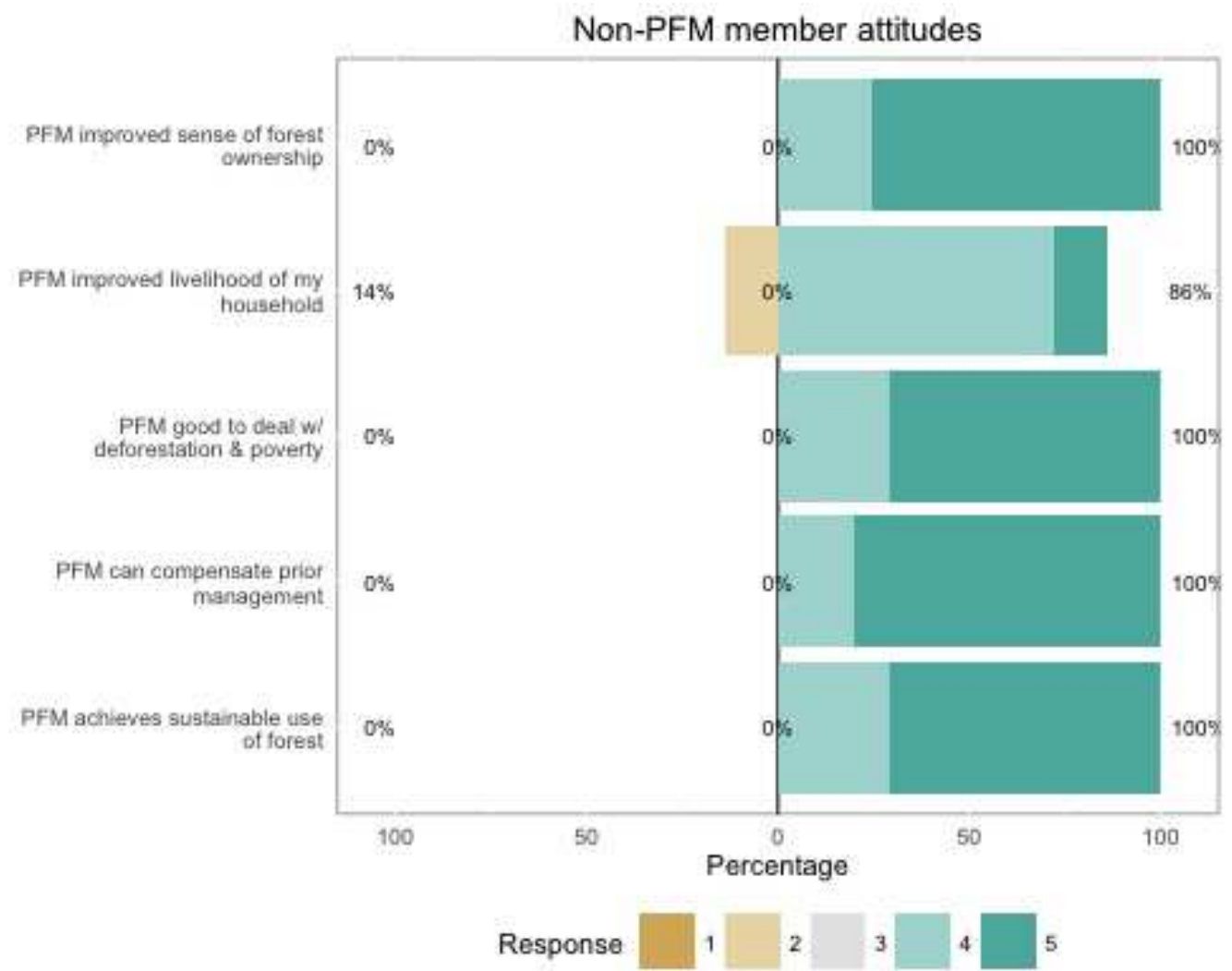

Note: $1=$ Strongly Disagree 2=Disagree 3= neutral 4=Agree 5=Strongly Agree

Figure 2. Non-PFM household's attitude towards PFM. 


\subsubsection{Attitude Towards Ecological Effect of PFM}

The likert scale Data collected through household survey from both PFM and non-PFM indicates that about $87 \%$ and $16 \%$ of PFM respondents were answered strongly disagree and disagree respectively; regarding the restoration of natural spring after the establishment of PFM while all (100\%) of non-PFM were strongly disagreed. All (100\%) of PFM and non-PFM respondents were strongly agreed that number of tree has increased after the establishment of PFM. About 91\% and $34 \%$ of respondents from PFM and non-PFM respectively, were strongly agreed that the establishment of PFM has increased the species of trees while $9 \%$ and $34 \%$ of respondents from PFM and non-PFM respectively agreed the increase in the species of trees after PFM establishment. In addition about $69 \%$ of PFM respondents were strongly agreed that the establishment of PFM has improved wildlife; and also about $31 \%$ of respondents from PFM were agreed PFM has improved wildlife. Unlikely, all (100\%) of nonPFM respondents were strongly agreed the improvement of wildlife after the establishment of PFM. $84 \%$ and $70 \%$ of respondents from PFM and non-PFM respectively were strongly agreed that the establishment of PFM has reduced soil erosion while $16 \%$ and $30 \%$ of PFM and non-PFM respondents respectively agreed the reduction of soil erosion after PFM establishment (Figures 3 and 4).

As it was revealed during interview with district forestry expert, the establishment of participatory forest management in the area was able to change the prior situation of the forest. Before the establishment of participatory forest, jello forest was characterrised by deforestation and sever soil erosion. There was an occasion in which a man was killed by the accident of the rock rolling down the mountain caused by soil erosion. Road blockage by the sliding rock down the mountain caused by soil erosion was also stated by the district forestry expert as one of the challenge frequently encountered by the peoples of the area.

However after the establishment of PFM in the Jello forest, the situation has changed. Owing to the restriction of open access of the forest and the under taken plantation activities the forest started to recover. Number of trees increased from time to time since PFM has been established in Jello forest. In account of the improved forest coverage problem of soil erosion has been decreased. Both PFM and non-PFM households were reported that they have positive attitude towards PFM (Figures 1 and 2) and its ecological effect (Figures 3 and 4).

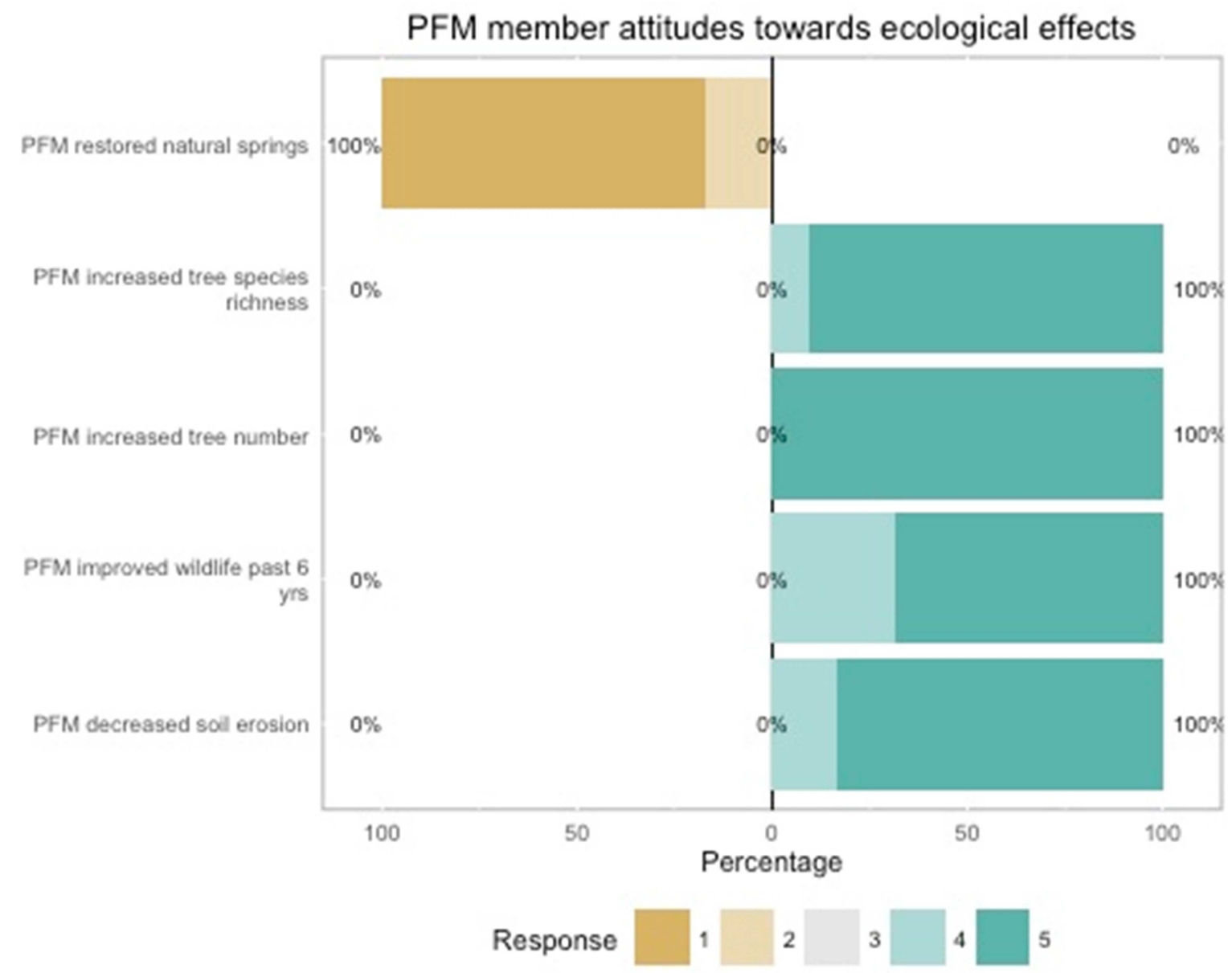

Note: $1=$ Strongly Disagree $2=$ Disagree $3=$ neutral 4=Agree 5=Strongly Agree

Figure 3. PFM household's attitude toward ecological effects of PFM. 


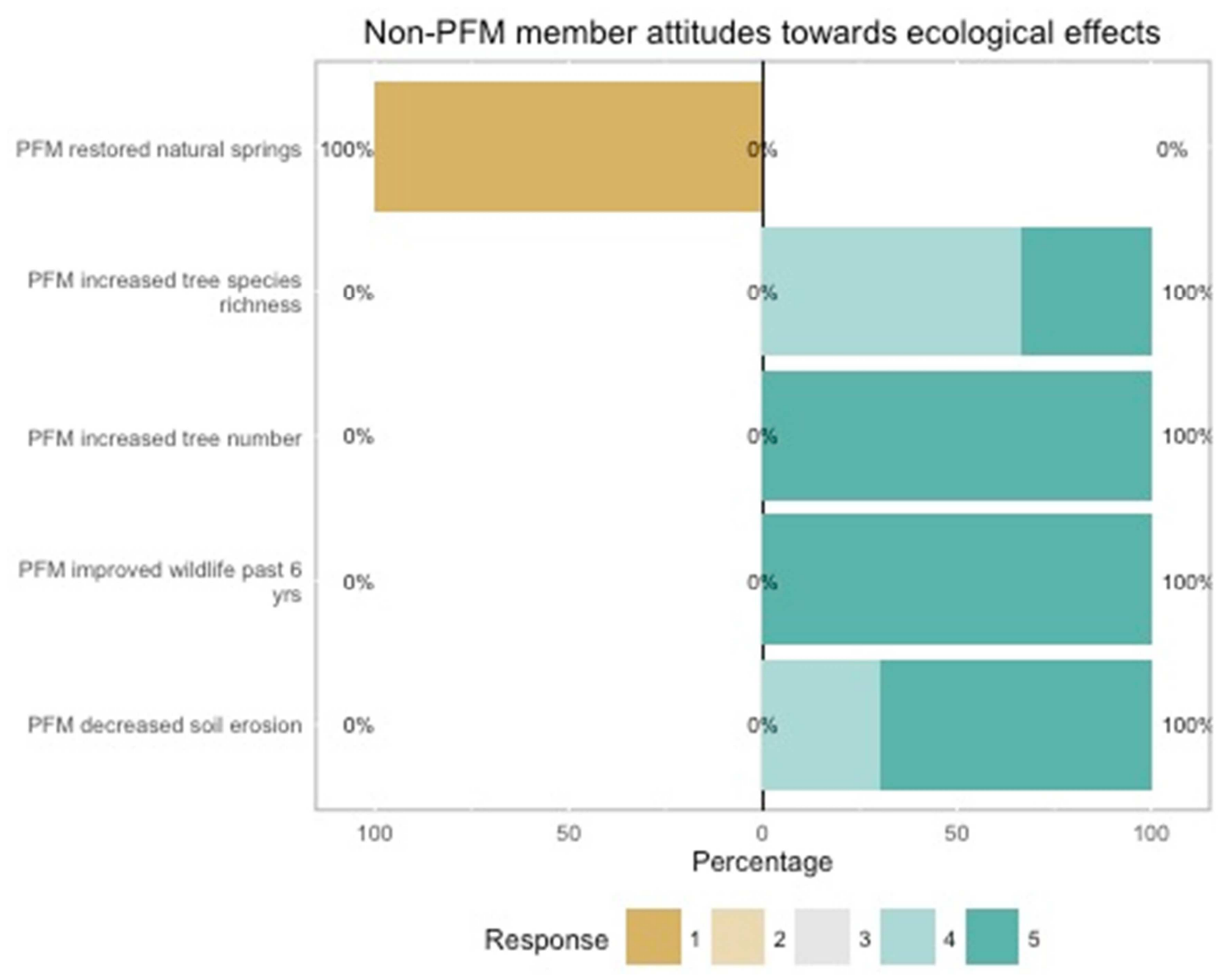

Note: $1=$ Strongly Disagree $2=$ Disagree $3=$ neutral $4=$ Agree $5=$ Strongly Agree

Figure 4. Non-PFM household's attitude toward ecological effects of PFM.

(Figures 3 and 4) clearly depicts the recorded scale of attitude held by both PFM and non-PFM households toward ecological effects of PFM. Accordingly, the result indicates that both groups of households have very positive attitudes towards ecological effects of PFM.

\section{Conclusion and Recommendation}

\subsection{Conclusion}

Depending on the finding of the study, it could be inferred that, local communities have a positive attitude towards the participatory forest management system irrespective of their membership status in PFM. Both participant and non participant member of the community has strong believe that More over local communities strongly agree that PFM has positive ecological effect.

This implies that PFM was able to overcome local community's resistance and they become aware of the participatory forest management. Unlike prior or top-down forest management approach, PFM was able to enhance local people's level of participation as it promotes equal participation for both female and male in forest management by granting the rights and responsibilities over forest resources.

Generally it could be concluded that PFM in Jello forest is effective in terms of creating favourable attitude towards forest conservation and stimulating a perception that PFM has positive ecological effects on the catchment area.

\subsection{Recommendation}

As the study indicates both non-PFM and PFM households have positive attitude towards the PFM approach and its ecological effect on the forest area. This indicates that it is right time to expand PFM into neighboring forest such as Muktar Mountain forest. Furthermore depending on the findings of the study it is recommendable that PFM is important for both the forest and the forest dependent peoples; as it serves the dual purpose of conserving the forest while contributing to the livelihood of the people. Thus, the further expansion of PFM in to other forest areas of the country will help to deal with the problem of deforestation and alleviation of forest dependency there by to insure sustainable utilisation of forest and forest resources.

\section{Acknowledgements}

Authors would like to extend sincerely and heartfelt thanks to their beloved ones (Ms. Hikma A. and Ms. Nahili M.) for their moral support to carry out this study. Further, much gratefulness goes to the local people who live around the 
study area for their hospitality and willingness to share their information.

\section{References}

[1] FAO, 2015, Assessment of Forests and Carbon stocks 19902015, Forestry paper 147, Rome.

[2] FAO, 2012, State of the World's Forests, Rome, Italy.

[3] Gatz Weiler, 2007, Deforestation of Ethiopia's Afromontane rain forest, (ZEF) Bonn University, German.

[4] Reusing, 2000, Change Detection of Natural High Forests in Ethiopia Using Remote Sensing and GIS Techniques, International Archives of Photogrammetry and Remote Sensing, Vol. XXXIII, Part B7, pp 1253-1258, Amsterdam.

[5] Mulugeta Lemenih and Melaku Bekele, 2008, Participatory Forest Management Best Practices Lesson Learnt and Challenges Encountered: The Ethiopian and Tanzanian Experience.

[6] MoARD\& WB, 2007, Ethiopia: Thematic Papers on Land degradation in Ethiopia, Ministry of Agriculture and Rural Development and World Bank, Addis Ababa, Ethiopia.

[7] Badage Bishaw, 2001, deforestation and land degradation on the Ethiopian high lands: a strategy for physical recovery, Ethiopian tree fund foundation (ETFF).

[8] Amogne Asfaw, 2014, forest resource management systems in Ethiopia: historical perspective, international journal of bio diversity and conservation, Vol, 6 (2), pp 121-131.

[9] Tsegaye Gobeze et al, 2009. Participatory Forest Management and Its Impacts on Livelihoods and Forest Status: The Case of Bonga Forest in Ethiopia. International Forestry Review 11 (3): 346-358.

[10] Winberg, 2010, Participatory Forest Management in Ethiopia, Practices and Experiences, Addis Ababa: Food and Agriculture Organization, Sub regional office for Eastern Africa (SFE).

[11] Alemayehu Negassa et al 2015, Performance of participatory forest management in Ethiopia: institutional arrangement versus local practices, Critical Policy Studies, Routledge.
[12] Ostrom, 1990, Governing the Commons: the Evaluations of Institutions for Collective Actions, Cambridge University Press.

[13] Farm-Africa and SOS' Sahel, 2007, the key stapes in establishing participatory forest management: a field manual to guide practitioner in Ethiopia, Best Practice series No. 1, Addis Ababa, Ethiopia.

[14] Yemiru, T, 2011, Participatory Forest Management for Sustainable Livelihoods in the Bale Mountains, Southern Ethiopia, Unpublished $\mathrm{PhD}$ thesis, Swedish University of Agricultural Sciences, Uppsala.

[15] Jello forest project management plan, 2009, Chiro, Ethiopia.

[16] MOA/FAO/UNDP, 1983, Generalized Agro climatic Map, Ethiopia, Assistance to Land Use Planning Project, FAO/UNDP-ETH/78/003, Addis Ababa, Ethiopia of Forest and Protected Area Management, 73-107.

[17] West Hararge ARDO, 2003, Different report, chiro

[18] Oromiya Forest and Wild life enterprise Hararghe Branch Office report, 2014.

[19] Solomon Tekalign and P. Suneetha, 2012, Livelihood Activities, Challenges and Strategies at Participatory Forest Management Sub-catchment in Hararge High lands, Eastern Ethiopia, ABHINAV Journal, Vol 2, p-25-37.

[20] Yamane, t, 1967, Statics: an introductory analysis, PP, 886887.

[21] Ajzen and Fishbein, 1977, Attitude-Behavior Relations Theoretical Analysis and Review of Empirical Research. Psychological Bulletin, 84 (5), 888-918.

[22] Ajzen, 2001, Nature and operation of attitudes. Annual Review of Psychology, 52 (27-58).

[23] Ambastha et al, 2007, Resource dependence and attitudes of local people toward conservation of Kabartal wetland: a case study from the Indo-Gangetic plains. Wetlands Ecology and Management, 15 (4), 287-302.

[24] Campbell et al, 2009, Building future scenarios and uncovering persisting challenges of participatory forest management in Chilimo Forest, Central Ethiopia, Journal of Environmental Management, 90 (2), 1004-1013. 